\title{
sciendo
}

DOI: $10.2478 /$ jolace-2021-0001

\section{The Shift to a Queer Pedagogy in the Italian-Language Classroom}

\author{
Giuseppe Formato \\ Lesley University \\ gformato@lesley.edu
}

\begin{abstract}
Instructors of Italian are tasked with teaching not only the language, but also the culture. However, critical matters such as sexual identity are frequently not addressed in the Italian-language classroom. Current Italian-language pedagogy solely focuses on language-acquisition proficiency via heteronormative discourses, ignoring the more-diverse reality of Italian culture. This article aims to showcase how using a queer pedagogy based on queer theory can affect learners' language acquisition and understanding of Italian culture. I used memoing and personal experiences as an Italian instructor to analyse the related literature. I propose that current pedagogy and curricula silence the lesbian-gay-bisexual-transgenderquestioning/queer-intersex-asexual (LGBTQIA+) community, causing exclusion, anxiety and sometimes harassment from others. Open discussion through queer pedagogy would create critical conversations, allowing for the inclusion of all learners and topics. Italian instructors should promote these conversations, question the standard Italian-language pedagogy and use materials that are inclusive of LGBTQIA+ members.
\end{abstract}

Keywords: Italian, queer pedagogy, Foucault, LGBTQIA+, language education

\section{Introduction}

Sexual identities within the cultures of Italian-language learners are frequently not addressed within the Italian-language classroom. Discourse, knowledge and power are linked, wiping certain learners' identities from the curriculum (Coda, 2018). Italian instructors must become conscious of differing identities and critique the field's accepted knowledge. Matters of race, ethnicity, class and, in this case, sexuality (Pennycook, 2001) within the scope of Italian culture (Formato, 2018, 2020a) must be managed progressively because language plays a role in forming, preserving and shifting conventions. This can be observed in Italian, where the grammar reflects traditional gender inequalities in power (Tosi, 2001). For example, adjectives take a masculine or a feminine ending depending on the gender of the nouns they accompany. In cases of mixedgender items, the masculine form predominates regardless of the quantity of items of either gender.

Language pedagogy introduces learners to linguistic and cultural aspects of the target language while encouraging reflection on comparable elements in the learners' languages and cultures. Thus, learning Italian fosters exploration of Italy's cultural norms. However, significant issues have been avoided in favour of sanitised topics (Osborn, 2006), especially considering sexual identities (Nelson, 2006). Thus, lesbian-gay-bisexualtransgender-questioning/queer-intersex-asexual (LGBTQIA+) learners' identities often are rendered invisible in the curriculum and materials (Camicia, 2016). Heteronormativity, the societal structures that perpetuate heterosexuality as natural and the norm (Atkinson \& DePalma, 2008), is pervasive in classrooms, materials and pedagogy (Paiz, 2015). Unfortunately, not enough is understood about how the junctions between LGBTQIA+ identity and Italian-pedagogic discourses may affect language 
acquisition and practice. This lack of understanding perpetuates heteronormative stereotypes that generate continual invisibility of LGBTQIA+ people in classrooms. It also implies that instructors may have trouble discovering ways to establish inclusive spaces for these learners (Paiz, 2019).

Although Italian-language pedagogy has the potential to disrupt normal practices (Formato, 2018, 2020b) and invoke 'a critical and self-reflective discourse for both students and teachers' (De Vincenti et al., 2007, p.67), Italian instruction often centres on proficiency. Instead, this standard practice should require critical reflection regarding Italian-language learning and pedagogy saturated with dominant assumptions and binaries (Coda, 2018). Current pedagogic constructs in Italian classrooms exert remarkable ideological dominance by instructing parts of Italian culture considered vital and useful to coming generations (Meyer, 2007). Therefore, instructors have the unique task of thwarting these socially constructed and permitted classifications. To offset these depictions, instructors should reveal and dismantle the concealed heterosexist curricula and learning materials.

The status quo provides no space for perspectives outside the norm, whether through the arts or everyday life. It actively erases these perspectives, sending a dark message of unwelcomeness. Sexual identities are essential elements of social identity that transcend sexual attraction and affect other aspects of lived experiences. In relation to language pedagogy, this notion suggests that sexual identities may become relevant in the classroom and influence the language-learning and -acquisition processes (Paiz, 2019). This article explores theoretical underpinnings for the use of queer pedagogy in the Italian-language learning classroom.

\section{Methodology}

I analysed literature in various fields relating to (1) queer theory, (2) queer pedagogy and (3) queer pedagogy in the language classroom. Sources ranged from unpublished theses to seminal works in books and peer-reviewed articles in international scholarly journals. Narratives used in this review were chosen based on their relevance to developing a critical means of teaching language and culture and presenting queer pedagogy and language teaching in a historical perspective. I aimed to determine key articulations and clusters of relevancies to construct a framework applicable to acquiring Italian. One significant analytic strategy I used was memoing - construction of a conceptual bridge between the written research and concepts used. I kept an audit trail using a journal to document memos that recounted my thoughts and recorded the basis for my choices during the research process (Merriam \& Tisdell, 2016). In addition to these thorough records of how I examined and understood the data, I reflected on my experiences as an Italian-language instructor (Lincoln \& Guba, 2000). Consensus across these multiple areas suggested a paradigm of queer pedagogy as a tool for a critical Italian-language pedagogy, as presented in the next sections.

\section{Results}

Queer Theory

Queer theory is principally about confronting normative and static perceptions of sexuality. It contends that sexual identity is neither static nor singular, but variable and ever-changing (Kissen, 2002). This perspective calls on Italian instructors to recognise and encourage sexual orientation and gender as notions that are fluid - not stagnant and permanent, as shown in language-learning materials' hegemonic reproductions of accepted familial and societal norms. This is a call to make these confrontations through 
critical pedagogy in Italian-language acquisition spaces. This perspective can be utilised as an investigation-centred method. It focuses on the presence of people in Italy, its diaspora and learners of all sexual identities studying the language and can critically examine and problematise language materials and information about social constructions as they relate to sexual identities. It also works to reduce the labelling and stigmatisation that result from categorising.

Italian instructors are encouraged to make a difference in their classes by vigorously examining the significance of words, expressions and ideas that might uphold the heteronormative status quo. Language is influential and encourages action - wielding a significantly genuine force in learners' lives (Burr, 2003). Queer theory necessitates Italian instructors break from pedagogic paradigms founded on rigid, inflexible and dualistic beliefs of gender, sexuality and sexual orientation. It is an essential expansion on critical pedagogy, social constructionism and emancipatory education, calling on instructors to adopt a queer pedagogical outlook.

Italian instructors have a dynamic position identifying experiences that encompass sexuality, sexual orientation and gender for their learners. The position demands that instructors assist in revealing inflexible standardising classifications, such as man/woman, masculine/feminine, learner/instructor and gay/straight (Meyer, 2007). Instructors must develop open discussion with learners outside these binaries. These discussions produce more reasonable, relevant, safe and socially unbiased atmospheres. To attain both sexual- and gender-identity justice, even small measures can make a difference. Instructors should allow time to discuss issues of homophobic, heterosexist, socially proctored gender norms and the subtle but sinister impact that language - in this case Italian - can have.

Queer Pedagogy

Italian instructors in the postmodern North American context are asked to work in hyperdiverse settings (Zacko-Smith, 2009). Queer pedagogy reflects the construction of knowledge, spread of ideas and crescendo of humans rationally, ethically and publicly. This queering of the classroom constructs spaces where discourse and critical conversation involving all identities - sexual or otherwise - and their sociocultural significance can be conducted in considerate ways (Paiz, 2017). It necessitates that Italian instructors be proficient in multiculturalism and diversity, both outside the context of the learning space where Italian is taught and within the complex realm of Italian culture. Instructors must submerge themselves in the world as it contemporaneously develops and advances around them and not perpetuate fossilised, hyperstereotyped constructs of cultural monoliths. They also must acknowledge their position as advisors, redefining experiences determined by requirements for social justice and equity to characterise truth for Italian-language learners (Formato, 2018). To overlook these constraints suggests that instructors will become archaic, unsuccessful, detrimental and socially discriminate (Formato, 2020a). None of these are adequate results for those who are genuinely dedicated to the vocation. Instructors commit a disservice to themselves, the profession, future learners and society by allowing spaces where unacceptance and conventional ideas are upheld.

Queer pedagogy affords instructors change from understanding LGBTQIA+ learners as 'other' to viewing sexuality without the use of firm markers and associated forming terms that could be instruments for harassment, discrimination and violence. Instructors should be aware of queer theory and conscious of its capacity to encourage acceptance and assist their teaching spaces. This begins by reconstructing the narrative of Italian speakers, dismissing stereotypes and offering images, samples, media and other items that depict 
the diverse reality of those who speak Italian. Queering heterosexual Italian instructors involves neither a shift in nor a demonstration of their individual sexuality. Instead, it requires them to be trained, proactive in describing the status quo and reflective on their heteronormative views regarding Italian-language pedagogy.

The toxic impacts of homophobia and heterosexism should illustrate to instructors how queer pedagogy can assist converting classrooms into spaces of language acquisition and critical consciousness. Current language classes do not take a stance on queer issues. However, a neutral stance is one of silence, ignorance and violence toward the queer community because recognised social norms, whether implicit or explicit, can lead to harassment. They can maintain a social order that favours conventional, heteronormative identities and performances over disregarded ones (Meyer, 2007).

Assuring the language used and materials selected for lessons do not support either sexual- or gender-identity status quo is a change all instructors can make. Such actions, even if implemented on a micro level, function to break down the normalisation of collectively manufactured classifications and establish more adaptable, peaceful and just agreements in their place. Furthermore, educating learners about LGBTQIA+ concerns can dismantle the power of binaries in both Italian and the learners' culture.

Queer Pedagogy in the Language Classroom

Practically every field has a transdisciplinary nature (Stokols, 2006), and Italianlanguage pedagogy is no exception. Classrooms are partly accountable for defining and reinforcing societal norms. In Italian-language classes, this may be evident in the sexist language, traditional notions of family, conservative representations of cultural and historical perspectives in pedagogic materials and lack of LGBTQIA+ depictions and contributions. Nature and logic must be reiterated within a society if its hegemony is to be maintained. Intrinsic in what the culture encourages, this narrative is perpetuated in all aspects of society, including the Italian-language classroom (Formato, 2018, 2020a). Italian instructors are assumed to either maintain the status quo or to define what is categorised as 'normal' in their teaching spaces and, thus, in greater society.

Italian-language instructors will undoubtedly have LGBTQIA+ learners in their classes. If instructors care about treating learners justifiably, then they are obligated to become informed on matters that are part of learners' everyday lives and identify aspects of queer culture - past and present - in Italian language and history. Italian instructors are a component of learners' everyday lives and must meet the shifting ways that learners both identify and convey themselves. I argue that this is currently not represented in Italianlanguage classes.

The frameworks that outline gender and sexuality are becoming increasingly distorted. Historically, the LGBTQIA+ were concerned with social acceptance and lessening the violence that arose from their struggles. Sexual orientation, gender and gender-identity matters started from the fight for recognition in the 1960s through the 1980s. It has since developed into a flourishing redefinition of sexual identity and sexuality itself. Today, matters that the LGBTQIA+ community previously could not afford to worry about can now operate openly and dynamically, including matters in the classroom.

In North America and Europe, the LGBTQIA+ population and their concerns have become more prominent and conventional. Popular media and the internet have provided them a degree of legitimacy. Society, including the Italian-language classroom, has reached an era where identities must be honoured and seen as invaluable instruments that augment globalised humanity. Social differences should be recognised, destigmatised and used in encouraging the approaches manifested in the realm of language pedagogy. 
Heterosexuality is the presumed social standard in dominant society. Queer pedagogy invites instructors to consider learners without assumption, reproducing what is considered 'natural'. A prevailing culture conveys messages of subservience at various degrees; this holds true for both Italian and the learners' own cultures. In this light, Italian instructors have an imperative role in the perception of Italian culture and how learners may relate to their own cultures. For example, an instructor might assume that a learner has a mother and father, the heterosexual stereotype of a family. This supposition consequently sends a message to everyone in the class concerning what is standard, predictable and recognised by society. This notion, adopted by instructors and incorporated into teaching materials, can trigger anxiety and oppression. Texts often devote entire chapters on this subject with limited (if any) mention of families that do not meet the definition of the typical family, thereby invalidating learners and certain aspects of the Italian, as well as the learners', culture.

\section{Foucault}

Theorists such as Michel Foucault (1980) demonstrated how language can be used to dominate and control. According to Foucault (1978/1990), discourse is constructive, affecting both language and personified acts. Language shapes the speaker's interpretations, performance and experiences. Applying it thoughtlessly can lead to repression, prejudice and aggression. Language is the instrument through which images and implications are created and negotiated - a fundamental method through which ideologies are transferred (Hawkins \& Norton, 2009). Understanding this approach can progress a hegemonic position in the (re)production of standards in Italian-language classrooms. Examining pedagogic methods that present the dominant discourses in the textbooks and curricula can help learners acknowledge the heterosexual models those discourses perpetuate and interpret as normal (Coda, 2018).

The practice of power continually generates knowledge, and knowledge likewise stimulates the effects of power (Foucault, 1980). Consequently, power is involved in the fabrication of knowledge, and knowledge in that of authority. Italian instructors must be conscious of Foucault's notions of discourse and power and how they generate certainties relative to issues such as identity. In language pedagogy, power, knowledge and discourse distinguish identities that support the norm and remove others, such as LGBTQIA+ identities (Coda, 2018). Configurations of knowledge as 'fact' can have significant repercussions in comprehending how particular identities are advantaged and become the standard over others. In Italian-language pedagogy, then, instructors' critical selfreflection is essential because it offers a view of the correlation between the individual and the social realm that emphasises both limitations and opportunities for social transformation (Hawkins \& Norton, 2009).

\section{Discussion}

Considerations for the Italian-Language Classroom

Queer analysis questions all identities and performances. It is advocated to assess influential dialogues regarding sexual and gender identities as regular or real (Coda, 2018). In pedagogy, prevalent heteronormativity dictates what is 'natural' gender and sexuality. Those who are unaligned with the accepted roles are subject to control over their performances (Pascoe, 2007). Pedagogies of inclusion only generate exclusion; thus, who is included must be examined. That is, who and what is depicted in relation to race, gender and class must be contemplated by presenting authentic images of queer identities in both the Italian and learners' culture. Because language is embedded with historical and cultural meanings, it affords problematising dominant discourses that exclude 
marginalised identities. Italian pedagogy can offer ways to question dominant assumptions and foster more equitable language-classroom spaces by disavowing standard proficiency-oriented practice and instead incorporating elements of queer theory and pedagogy (Atkinson \& DePalma, 2008). This ideology can then invoke critical thinking around the practices that normalise heterosexuality in pedagogy and silence LGBTQIA+ identities in classrooms (Coda, 2018).

Italian-language learning encompasses grappling with myriad meanings and making one's way without traditional anchoring points. It requires a heightened awareness of the centrality of language, the cultural specificity of knowledge and the ways in which language and knowledge are infused with relations of power (Nelson, 2009). Instructors must reflect on how classroom practices may reify norms within both Italy's and the learners' cultures. Students are not homogenous. They possess multiple identities regulated and (re)produced through discourses. Instructors must constantly reflect how they can open a space for all identities and forms of knowledge.

Norms produce knowledge about identities. By encouraging students to critically reflect on those norms, instructors can consider the ways in which cultural norms vary. Exploration of other ways of thinking and being in the world can foster democracy and social justice (Coda, 2018). Although proficiency is a relevant aspect of Italian pedagogy, the influence and importance of a critical, queer pedagogy must not be overlooked (Formato, 2018).

There are tangible concerns for LGBTQIA+ learners. For instance, permitting heteronormative (i.e. homophobic) beliefs to go uncontested also permits detrimental and unsafe behaviours (Paiz, 2019). Italian-language instructors have not sufficiently addressed the queering of their practice or created spaces where all identities are problematised relative to dominant social discourses.

Classrooms need a queer-knowledgeable pedagogy, primarily one in which all identities are patrolled by hegemonic social discourses through a variety of resources, such as language. Critical consciousness of the necessity to stress all identities, not just LGBTQIA+ identities, is essential for both language learning and teaching (Nelson, 2006). The result of a queer-pedagogical tactic would lead learners to address their own sexual identities, communicate with LGBTQIA+ persons in empathetic and relevant ways and deconstruct LGBTQIA+ identities in their everyday lives and in the mainstream media of Italian culture. This is significant because there is much at stake in heteronormative Italian learning spaces - even ones that are inadvertently so.

The sanitised, homophobic and neutral world continues to be perpetuated. Learners must be prepared to participate in LGBTQIA+ matters, content and discussions in Italianlanguage classrooms as a part of lived practices. This perspective reflects reality, rather than the hegemonic discourse. Reluctance to construct a secure space for these conversations can have detrimental outcomes, such as continuously regarding LGBTQIA+ identities as forbidden or 'other'.

Moore (2016) underscored the perils of not critically reflecting on practice in a manner that recognises the differed environment of the classroom for LGBTQIA+ people. He detailed a queer-investigation methodology that allows instructors to be more cognisant of social questions, such as those about weekend plans or out-of-class events, which may generate pressures for LGBTQ+ language learners. Learners must decide how to reply honestly or guarding their sexual identities. They sometimes disguise their sexual identity in classes, fearing retribution, reprisals, and exclusion. This obligates Italian instructors to reflect on how to introduce and integrate LGBTQIA+ material into queered language classes (Piaz, 2019). 
Conversations on queer identity can produce components of thematic-based programs permitting the integration of other prejudiced topics, such as homophobia. However, this does not benefit queer identity. Matters of sexual characteristics should not be addressed in isolation, positioning unwarranted emphasis on them. Instead, acknowledgment of sexual identities must be presented as part of a broader exercise of justice and antidiscrimination throughout the curricula and as part of a far-reaching critical pedagogic scheme. This has consequences for foreign-language instruction, which emphasises views and belief patterns of other cultures instead of the local culture (De Vincenti et al., 2007).

Preventing such conversations propagates the taboo and does not acknowledge abstract changes that may be happening in Italian language and culture. Supporting these conversations affords learners the chance to articulate genuine ideas and become autonomous speakers of Italian. A linguistic pedagogical discourse must be encouraged one that questions normative positions penetrating the composition of Italian language and culture, performed and strengthened daily through images and societal norms. If identities are assumed to be discursively produced, and if Italian plays an important role in articulating identities, then tactics that permit discovery within the limitations of cultural linguistic constructions must be developed and discussed in the classroom, as opposed to pretending they do not exist (De Vincenti et al., 2007).

Such discovery, including questions about sexual identities, starts in the beginner stages of language acquisition. Conversations focusing on ideas such as family and relationships can create profound discussion about sexual identities and can be investigated within fundamental Italian-language exercises. In beginner classes this theoretical dialogue may take place in English. The approach implemented may depend on the instructor's personal inclination; however, the use of a common language (English, in the North American context) should not be rejected if it supports the learners' acquisition and understanding of the language and cultural context (De Vincenti et al., 2007).

\section{Classroom Materials and Applications}

Materials have been created to sidestep issues that establish queer voices in Italian teaching spaces, such as family and dating. Evasion may seem to be a simple, impartial approach that many Italian instructors and textbook publishers practise. Nevertheless, evading topics is symptomatic of an ideological position that, in this case, is heteronormative by preserving a monosexual worldview (Liddicoat, 2009) in the Italian and predominant North American cultures. Indeed, male and female roles need be discussed to learn about culture, but there is also a queer Italian culture. Otherwise, queer learners may believe they are acquiring a language from places where they and related ideas are not welcome. Therein lies a hidden curriculum of conformity in Italian classes (Formato, 2018, 2020a). Learners who do not match the textbook-displayed identity choices may face problems in their efforts to acquire the language or become effective Italian-language speakers. Further, sexual and gender identities presented as legitimate or respected in the target context may brand learners who identify alternatively as illegitimate users of the foreign language (Paiz, 2019).

Queering Italian-language pedagogic resources requires approaches that are vulnerable to the demands and linguistic abilities of the Italian-language learners. For instance, lower-level learners may increase proficiency by utilising authentic materials scaffolded by the instructor through in-class activities. Scaffolding includes cautious modifications of materials, making them more linguistically suitable, allowing more critical thinking and displaying more diverse relationships and situations. This opposes the heteronormative, textbook-provided and sanitised examples of traditional relations. 
Moreover, the instructor must push more in-class dialogue to spotlight queer identities and manifestations, promoting diversity (Merse, 2015).

Class materials also must be queered, and Italian-language instructors must be adequately trained to carry out this crucial effort with little encouragement from supervisors. Such alterations may seem unnecessary because they are not mainstream or trivial because well-educated and well-trained language instructors should not require assistance. However, they are crucial because commercially offered materials often serve as an influential scaffold for beginning-Italian instructors (Grossman \& Thompson, 2008) and may falsely legitimise material examples as inflexible. Furthermore, time constraints commonly restrict where and how instructors move away from the delegated text.

Textbooks

Textbooks favour heteronormative discourses in Italian-language teaching spaces (Paiz, 2015). Conventional curricular materials - mass produced by for-profit publishers - often reify discourses that determine the accessible range of identity alternatives for learners and suppress unconventional voices (Paiz, 2017). Italian-learning materials seldom mention queer voices, either in book characters or aspects of Italian culture and society. For example, exercises do not demonstrate relationships or issues that fall outside of a heteronormative perspective. Instead, examples that could lead to discussion and that acknowledge the existence of marginalised voices serve learners and afford them a just narrative.

Textbooks can be used to introduce queer cultural icons and important historic figures in Italian history. Many famous Italians are mentioned throughout standard language textbooks. Similarly, discussion of famous queer Italians - from the arts, such as Botticelli, Caravaggio, da Vinci, Michelangelo and Donatello; to film, such as Pasolini, Zeffirelli and Visconti; to fashion icons, such as Versace, Gabbana and Armani - could be created both in English and intermediate- and advanced-level Italian. If these famous figures are not positively presented and framed as contributing to Italian culture, then their absence from and disparity with mainstream Italian culture will further contribute to estranging queer culture.

\section{Assignments}

The Italian-language teaching space is a constructive area to discover sexual identities because language learning requires contributions in different assignments and communicative exercises, such as role playing. Learners are urged to envision themselves in various circumstances and roles. Thus, the exploration of identities is an essential, although not always explicitly recognised, part of the language space (De Vincenti et al., 2007). It is a potential but currently unutilised tool to discuss and understand queer culture and experiences in both the Italian and the learners' contexts. Role-playing exercises that focus on aspects of communicative competence to acquire Italian adopt neutral identities, thereby silencing queer voices and perpetuating harmful perceptions of queer people. This results in missed opportunities for communicative exercises that both facilitate language acquisition and open learning spaces to hear other marginalised perspectives.

Life-description assignments are powerful instruments for queering the Italianlanguage classroom. Learners can describe, legitimise and share their unique life experiences with the class, as opposed to leaving these experiences undiscussed and silenced, which continues the heteronormative power paradigms. Additionally, class exercises can provide more general cultural responses relating to both Italian and North American culture. 
Italian-language instructors must discover ways to mix LGBTQIA+ matters into their courses, understanding that LGBTQIA+ content might coincide with prevailing curricula that emphasise themes such as cultural diversity, celebrities and workplace life (Merse, 2015). However, thematic units (health, family, greetings, sports, etc.) are more commonly presented in a narrow, heteronormative light that perpetuates outdated and destructive paradigms within the Italian-language classroom to learners' detriment.

\section{Conclusion}

Integrating queer pedagogy, and therefore queer theory, necessitates an interrogation of the knowledge that influences instructors' thinking and practice. Queer pedagogy is a chance to promote a group atmosphere for critical and self-reflective dialogue among instructors and learners within the context of Italian language and culture (Formato, 2018). Acknowledging the interrelation between the Italian language and its culture is vital. Because linguistic constructions build social experiences, the Italian language and those who teach it embody instruments to either support or question heteronormative sociocultural values.

Queering the Italian-language pedagogy can invoke learners' critical thinking around issues related to sexual identities. Supporting materials and a curriculum that enable linguistic and reflective discovery are needed (Formato, 2020b) to establish new methods in the classroom. Italian instructors should provide texts depicting nonheteronormative people having the same relationships, levels of enthusiasm regarding love and difficulties inherent in heterosexual relationships (De Vincenti et al., 2007). Although instructors are not always afforded the time to adapt all texts, awareness of these disparities is important in validating issues and acknowledging queer voices in the learners' culture and lives.

The reality of Italian culture is diverse. Representations of the Italian queer reality can be discussed in thematic units at different levels of linguistic proficiency or in English. These units explain the current situation in Italy, possibly sparking critical discussion in a comparison to the learner's culture. Discussion of inclusion in Italian textbooks may include LGBTQIA+ rights, history, recognition, family, identity expression, activist groups, public campaigns, living conditions and public opinion. In this way, queer pedagogy can offer language acquisition through a critical perspective, giving marginalised learners a voice.

\section{Conflict of interests}

The author declares that they have no conflict of interest.

\section{References}

Atkinson, E., \& DePalma, R. (2008). Imagining the homonormative: Performative subversion in education for social justice. British Journal of Sociology of Education, 29(1), 25-35. https://doi.org/10.1080/01425690701737333

Burr, V. (2003). Social constructionism. Routledge.

Camicia, S. P. (2016). Critical democratic education and LGBTQ-inclusive curriculum: Opportunities and constraints. Routledge.

Coda, J. (2018). Disrupting standard practice: Queering the world language classroom. Dimension, 2017, 74-89.

De Vincenti, G., Giovanangeli, A., \& Ward, R. (2007). The queer stopover: How queer travels in the language classroom. Electronic Journal of Foreign Language Teaching, $4(1), 59-64$. 
Formato, G. (2018). Instilling critical pedagogy in the Italian language classroom. Journal of Language Teaching and Research, 9, 1117-1126. http://dx.doi.org/10.17507/jltr.0906.01

Formato, G. (2020a). Arte povera as a tool in critical Italian-language pedagogy. $\begin{array}{llll}\text { International Journal of Linguistics, } & 12, & 233-251 .\end{array}$ https://doi.org/10.5296/ijl.v12i4.17423

Formato, G. (2020b). Eco-justice pedagogy all'Italiana: Radical Italian art in the Italianlanguage classroom. Theory and Practice in Language Studies, 10, 1501-1509. http://dx.doi.org/10.17507/tpls.1012.01

Foucault, M. (1990). The history of sexuality. Vintage Books. (Original work published 1978)

Foucault, M. (1980). Power/knowledge: Selected interviews and other writings, 1972-1977 (C. Gordon, Ed.). Harvester Press.

Grossman, P. \& Thompson, C. (2008). Learning from curriculum materials: Scaffolds for new teachers? Teaching and Teacher Education, 24, 2014-2026.

Hawkins, M., \& Norton, B. (2009). Critical language teacher education. In A. J. Burns, \& J. I. Richards (Eds.), The Cambridge guide to second language teacher education (pp. 3039). Cambridge University Press.

Johansson, T. (2007). The transformation of sexuality: Gender and identity in contemporary youth culture. Ashgate.

Kissen, R. M. (Ed.). (2002). Getting ready for Benjamin: Preparing teachers for sexual diversity in the classroom. Rowan \& Littlefield.

Liddicoat, A.J. (2009). Sexual identity as linguistic failure: Trajectories of interaction in the heteronormative language classroom. Journal of Language, Identity, and Education, 8, 191-202.

Lincoln, Y. S., \& Guba, E. G. (2000). Paradigmatic controversies, contradictions, and emerging confluences. In N. K. Denzin \& Y. S. Lincoln (Eds.), Handbook of qualitative research (2nd ed., pp. 163-188). Sage.

Merriam, S. B., \& Tisdell, E. J. (2016). Qualitative research: A guide to design and implementation. Jossey-Bass.

Merse, T. (2015). Queer-informed approaches and sexual literacy in ELT: Theoretical foundations and teaching principles. Language issues, 26(1), 13-20.

Meyer, E. (2007). But I'm not gay: What straight teachers need to know about queer theory. In N. Rodriguez \& W. Pinar (Eds.), Queering straight teachers: Discourse and identity in education (pp. 15-32). Peter Lang.

Moore, A. R. (2016). Inclusion and exclusion: A case study of an English class for LGBT learners. TESOL Quarterly, 50, 86-108. https://doi.org/10.1002/tesq.208

Nelson, C. D. (2006). Queer inquiry in language education. Journal of Language, Identity \& Education, 5, 1-9. https://doi.org/10.1207/s15327701jlie0501_1

Nelson, C. D. (2009). Sexual identities in English language education. Routledge.

Osborn, T. A. (2006). Teaching world languages for social justice: A sourcebook of principles and practices. Lawrence Erlbaum Associates.

Paiz, J. M. (2015). Over the monochrome rainbow: Heteronormativity in ESL reading texts and textbooks. Journal of Language and Sexuality, 4(1), 77-101. https://doi.org/10.1075/jls.4.1.03pai

Paiz, J. M. (2017). Queering ESL teaching: Pedagogical and materials creation issues. TESOL Journal, 9, 348-367. https://doi.org/10.1002/tesj.329 
Paiz, J. M. (2019). Queering practice: LGBTQ+ diversity and inclusion in English language teaching. Journal of Language, Identity, and Education, 18, 266-275. https://doi.org/10.1080/15348458.2019.1629933

Pascoe, C. J. (2007). Dude, you're a fag. University of California Press.

Pennycook, A. (2001). Critical applied linguistics: A critical introduction. Lawrence Earlbaum Associates.

Stokols, D. (2006). Toward a science of transdisciplinary action research. American Journal of Community Psychology, 38, 63-77. https://doi.org/10.1007/s10464-0069060-5

Tosi, A. (2001). Language and society in a changing Italy. Multilingual Matters.

Zacko-Smith, J. D. (2009). The leader label: Leadership in a hyper diverse world. VDM Verlag.

\section{Contact:}

Giuseppe Formato, PhD.

Lesley University

29 Everett Street

Cambridge, MA 02138

gformato@lesley.edu 